\title{
Pronunciation of Indian Words
}

Cities and well-known persons of recent history are written in their Anglicized form; on the other hand, gods and shrines are written in the internationally common transcription of Sanskrit, Hindī (H.), Nepālī (N.), or Tamil. This transcription oriented to Devanāgarī writing enables a precise pronunciation, in which two rules are especially to be observed.

1. A line over a vowel indicates its length: bhüta pronounced like the English "mood"; both $e$ and $o$ are always long.

2. An $\mathrm{S}(\dot{s}, \mathrm{~s})$ is pronounced like the English "sh," when it is provided with an additional sign: śästra like shästra and mokșa like moksha; without a diacritical mark, it is always a sharp (dental) S.

In addition, the following rules of pronunciation apply:

$C$ like the English ch: cakra like church

$J$ like the English $j$ : jātrā like jungle

$Y$ like the English y: yogi like yogurt

$V$ like the English v: Viṣnu like vine.

A dot under a consonant (except $m$ ) indicates retroflex pronunciation, i.e., with the tongue bent back.

A dot or a tilde over an $\mathrm{N}(\dot{n}, \tilde{n})$ and a dot under an $\mathrm{M}(m)$ indicate the conformed nasalization of the succeeding consonants (see the English "end").

A dot under an $\mathrm{R}(r)$ is often pronounced ri (mahärși as "Mahārishi").

An $\mathrm{H}$ behind a consonant is a clearly strengthening aspiration of the consonant (see the English "Tea"). 
